\title{
Contrasting Roles of Dopamine and Noradrenaline in the Motivational Properties of Social Play Behavior in Rats
}

\author{
EJ Marijke Achterberg ${ }^{1,4}$, Linda WM van Kerkhof ${ }^{2,4}$, Michela Servadio², Maaike MH van Swieten², \\ Danielle J Houwing ${ }^{2}$, Mandy Aalderink ${ }^{2}$, Nina V Driel ${ }^{2}$, Viviana Trezza ${ }^{3}$ and Louk JMJ Vanderschuren ${ }^{*, 1,2}$ \\ 'Department of Animals in Science and Society, Division of Behavioural Neuroscience, Faculty of Veterinary Medicine, Utrecht University, Utrecht, \\ The Netherlands; '2Department of Translational Neuroscience, Brain Center Rudolf Magnus, University Medical Center Utrecht, Utrecht, \\ The Netherlands; ${ }^{3}$ Department of Science, Section of Biomedical Sciences and Technologies, University 'Roma Tre', Rome, Italy
}

Social play behavior, abundant in the young of most mammalian species, is thought to be important for social and cognitive development. Social play is highly rewarding, and as such, the expression of social play depends on its pleasurable and motivational properties. Since the motivational properties of social play have only sporadically been investigated, we developed a setup in which rats responded for social play under a progressive ratio schedule of reinforcement. Dopaminergic neurotransmission plays a key role in incentive motivational processes, and both dopamine and noradrenaline have been implicated in the modulation of social play behavior. Therefore, we investigated the role of dopamine and noradrenaline in the motivation for social play. Treatment with the psychostimulant drugs methylphenidate and cocaine increased responding for social play, but suppressed its expression during reinforced play periods. The dopamine reuptake inhibitor GBR-12909 increased responding for social play, but did not affect its expression, whereas the noradrenaline reuptake inhibitor atomoxetine decreased responding for social play as well as its expression. The effects of methylphenidate and cocaine on responding for social play, but not their play-suppressant effects, were blocked by pretreatment with the dopamine receptor antagonist $\alpha$-flupenthixol. In contrast, pretreatment with the $\alpha 2$-adrenoceptor antagonist RX82 1002 prevented the play-suppressant effect of methylphenidate, but left its effect on responding for social play unaltered. In sum, the present study introduces a novel method to study the incentive motivational properties of social play behavior in rats. Using this paradigm, we demonstrate dissociable roles for dopamine and noradrenaline in social play behavior: dopamine stimulates the motivation for social play, whereas noradrenaline negatively modulates the motivation for social play behavior and its expression.

Neuropsychopharmacology (2016) 4I, 858-868; doi:I0.1038/npp.2015.212; published online 2 September 2015

\section{INTRODUCTION}

The experience of social interactions during post-weaning development (ie, childhood and adolescence in humans, roughly equivalent to the juvenile and adolescent stages in mammals) is critical for social and cognitive development (Panksepp et al, 1984; Vanderschuren et al, 1997; Špinka et al, 2001; Pellis and Pellis, 2009; Graham and Burghardt, 2010; Baarendse et al, 2013a; Vanderschuren and Trezza, 2014). During this developmental period, a characteristic, highly vigorous form of social interaction, ie, social play behavior, is abundantly expressed in most mammalian species (Panksepp et al, 1984; Vanderschuren et al, 1997; Pellis and Pellis, 2009). Social play behavior is highly

*Correspondence: Professor LJMJ Vanderschuren, Department of Animals in Science and Society, Division of Behavioural Neuroscience, Faculty of Veterinary Medicine, Utrecht University, Yalelaan 2, 3584 CM Utrecht, The Netherlands, Tel: +3I 30 2535239, Fax: +3I 302537997,

E-mail: I.j.m.j.vanderschuren@uu.nl

${ }^{4}$ These authors contributed equally to this work.

Received 10 April 2015; revised I July 2015; accepted 2 July 20I5; accepted article preview online 15 July 2015 rewarding (Vanderschuren, 2010; Trezza et al, 2011) and its expression is modulated through neural systems also implicated in other types of reward, such as food, sex, and drugs of abuse (Trezza et al, 2010; Siviy and Panksepp, 2011). Reward processes consist of pleasurable, incentive motivational, and learning components, which are mediated through different neural mechanisms (Berridge et al, 2009). For example, opioids and endocannabinoids have been implicated in the pleasurable properties of rewards, whereas dopamine is thought to mediate their motivational aspects (Kelley, 2004; Barbano and Cador, 2007; Robbins and Everitt, 2007; Berridge, 2007; Salamone and Correa, 2012; Berridge and Kringelbach, 2015).

The pleasurable properties of social play behavior have previously been studied using place conditioning, in which young rats develop a preference for an environment associated with social play if the play encounter is perceived as pleasurable (Calcagnetti and Schechter, 1992; Crowder and Hutto, 1992; Douglas et al, 2004; Thiel et al, 2008; Trezza et al, 2009a; Peartree et al, 2012). However, the incentive motivational properties of social play have only been sporadically investigated in the past (Mason et al, 1962; Humphreys 
and Einon, 1981; Normansell and Panksepp, 1990). Therefore, in order to be able to measure the motivational properties of social play behavior, we developed an operant conditioning task, in which rats responded for brief periods of social play under a progressive ratio (PR) schedule of reinforcement (Hodos, 1961; Richardson and Roberts, 1996). In this setup, observation of behavior during reinforced periods also allowed for the assessment of the expression of social play.

Previous studies have shown that social play behavior is modulated by dopaminergic and noradrenergic neurotransmission. For example, treatment with dopamine receptor agonists and antagonists alters the expression of social play behavior (Niesink and Van Ree, 1989; Siviy et al, 1996; Vanderschuren et al, 2008; Trezza and Vanderschuren, 2009). In addition, the stimulation of social play by endocannabinoids, ethanol, and nicotine depends upon dopamine receptor stimulation (Trezza and Vanderschuren, 2008, 2009; Trezza et al, 2009b). Administration of the $\alpha 2$-adrenoreceptor agonist clonidine and the $\alpha 2$-adrenoceptor antagonist RX821002 reduced and enhanced social play, respectively (Normansell and Panksepp, 1985; Siviy et al, 1994; Siviy and Baliko, 2000). Furthermore, amphetamine, methylphenidate, and the noradrenaline reuptake inhibitor atomoxetine reduced social play through stimulation of $\alpha 2$-adrenoceptors (Beatty et al, 1982; Vanderschuren et al, 2008; Achterberg et al, 2014). However, it is unknown whether dopamine and noradrenaline are involved in the motivational properties of social play behavior. On the basis of its well-known role in incentive motivational processes (Kelley, 2004; Barbano and Cador, 2007; Robbins and Everitt, 2007; Berridge, 2007; Salamone and Correa, 2012), it is likely that dopamine modulates the motivational properties of social play. Noradrenergic neurotransmission has traditionally been implicated in attention and arousal processes (Berridge and Waterhouse, 2003; Aston-Jones and Cohen, 2005), rather than motivation or reward. However, emerging work in rodents (Ventura et al, 2008) and primates (Bouret and Richmond, 2015) has indicated that noradrenergic neurotransmission may also modulate reward processes. Indeed, our recent work implicates prefrontal, amygdala, and habenula noradrenaline in social play behavior (Achterberg et al, 2015), which hints at the possibility that limbic noradrenaline is involved in certain emotional aspects of this behavior.

In the present study, we therefore investigated whether dopamine and noradrenaline are involved in the motivational aspects of social play behavior. To this aim, we tested the effects of the dopamine/noradrenaline reuptake inhibitor methylphenidate, the monoamine reuptake inhibitor cocaine, the dopamine reuptake inhibitor GBR-12909, the noradrenaline reuptake inhibitor atomoxetine, the dopamine receptor antagonist alpha-flupenthixol, and the $\alpha 2$-adrenoceptor antagonist RX821002, alone or in combination, on responding for social play behavior under a PR schedule of reinforcement. We also assessed the expression of social play behavior during reinforced play periods. We hypothesized that dopaminergic neurotransmission is involved in the motivational properties of social play, and that by suppressing social play, increased noradrenaline neurotransmission reduces responding for social play.

\section{MATERIALS AND METHODS}

\section{Animals}

Male Wistar rats (Charles River, Sulzfeld, Germany) arrived in our animal facility at 21 days of age and were housed in groups of four in $40 \times 26 \times 20 \mathrm{~cm}(l \times w \times h)$ Macrolon cages under controlled conditions (temperature $20-21^{\circ} \mathrm{C}, 60-65 \%$ relative humidity, and $12 / 12 \mathrm{~h}$ light cycle with lights on at $0700 \mathrm{~h}$ ). Food and water were available ad libitum. All experiments were approved by the Animal Ethics Committee of Utrecht University and were conducted in accordance with Dutch laws (Wet op Dierproeven, 1996) and European regulations (Guideline 86/609/EEC).

\section{Drugs}

Methylphenidate hydrochloride, cocaine hydrochloride (BUFA, Castricum, The Netherlands), atomoxetine hydrochloride, RX821002 hydrochloride (Tocris Bioscience, Bristol, UK), and $\alpha$-flupenthixol dihydrochloride (SigmaAldrich, Schnelldorf, Germany) were dissolved in saline. GBR-12909 dihydrochloride (Sigma-Aldrich) was dissolved in MilliQ water. Methylphenidate, cocaine, and GBR-12909 were administered subcutaneously (s.c.). Atomoxetine, $\alpha$-flupenthixol and RX821002 were administered intraperitoneally (i.p.). Drug doses and pretreatment intervals were based on previous studies (Baarendse et al, 2013a, b; Baarendse and Vanderschuren, 2012; Trezza and Vanderschuren, 2009; Vanderschuren et al, 2008; Achterberg et al, 2014). Drug doses were calculated as salt. Drugs were administered $30 \mathrm{~min}$ before testing, except when methylphenidate or cocaine treatment was combined with $\alpha$-flupenthixol or RX821002 treatment, in which case $\alpha$-flupenthixol and RX821002 were administered 30 and $15 \mathrm{~min}$ before methylphenidate or cocaine administration, respectively. In view of the importance of the neck area in the expression of social play behavior (Pellis and Pellis, 1987; Siviy and Panksepp, 1987), s.c. injections were administered in the flank.

\section{Apparatus}

Behavioral testing was conducted in an operant conditioning chamber (Med Associates, Georgia, VT, USA) divided into two equally sized compartments $(25 \times 30 \times 25 \mathrm{~cm}, l \times w \times h)$. The compartments were separated by a Plexiglas wall with 42 small holes (diameter, $\varnothing=0.5 \mathrm{~cm}$ ) and an automated metal door in the middle. Both compartments had a metal grid floor and a Plexiglas lid which contained a house light (2 W). One compartment was equipped with two $4.8-\mathrm{cm}$-wide retractable levers, located on opposite sides of the compartment. Above each lever was a cue light $(2.5 \mathrm{~W})$. One lever was designated as the active lever and the other as the inactive lever; allocation of the left or right lever as active was counterbalanced between animals. Experimental events and data recording were controlled using Med PC software (Med Associates).

\section{Operant Conditioning}

All experiments were performed under red light conditions. Animals were randomly paired with a test partner from 
another home cage. Animals in a test pair did not differ by more than $10 \mathrm{~g}$ in body weight at the start of the experiment. A test pair consisted of one experimental animal and its stimulus partner. At 24 days of age, test pairs were habituated to the test cage for $10 \mathrm{~min}$. During the habituation session, the animals could freely explore the entire apparatus. After the habituation session, animals were isolated for $24 \mathrm{~h} /$ day for 5 consecutive days/week, except in the first validation experiment, in which we also included a group of animals isolated for $2 \mathrm{~h} /$ day for 5 days/week. Next, the animals received two shaping sessions on two consecutive days. During these shaping sessions, the cue light was presented, the lever retracted and the door opened when the experimental animal approached the active lever. Rats were allowed to interact for 2 min after which the door closed and each rat was placed back into its starting compartment by the experimenter. This procedure was repeated seven times in each shaping session. In addition, if an animal did not perform any active lever presses during acquisition sessions, it received an additional shaping session later that day or on the next day.

On the fourth day, the lever pressing sessions $(20 \mathrm{~min}$ ) commenced under a fixed ratio (FR)-1 schedule of reinforcement. Under this FR-1 schedule of reinforcement, each active lever press resulted in presentation of the cue light, retraction of both levers, and opening of the door, after which animals were allowed to freely interact for $2 \mathrm{~min}$. After $2 \mathrm{~min}$, the door automatically closed and the house light was illuminated during a $25 \mathrm{~s}$ inter-trial interval. During this interval, the experimenter placed each rat back into its starting compartment. After acquisition of the task under the FR-1 schedule (ie, when an animal obtained at least six out of eight possible rewards on two consecutive days), a PR schedule of reinforcement was introduced. Under this schedule, the animals had to meet a response requirement on the active lever that progressively increased after every earned reward (1, 2, 4, 6, 9, 12, 15, 25, etc.; Hodos, 1961; Richardson and Roberts, 1996). When rats met the response requirement, the cue light was illuminated, both levers retracted and the door opened for $1 \mathrm{~min}$, during which the animals could freely interact. A PR session continued until an animal failed to obtain a reward within $10 \mathrm{~min}$. Animals received one session per day, for 5 consecutive days/week. During the other 2 days/week animals were socially housed with their original cagemates. After responding had stabilized, defined as obtaining at least six rewards on three consecutive days with a variation of no more than two rewards, drug treatment started according to a Latin square design. Inactive lever presses were recorded, but had no programmed consequences.

During earned social interactions, behavior of the playing rats was assessed online using the Observer 5.1 software (Noldus Information Technology B.V., The Netherlands). In addition to the online analysis, behavior of the animals was recorded using a camera with zoom lens, video tape recorder, and television monitor. Three behavioral elements were scored (Panksepp et al, 1984; Vanderschuren et al, 1997; Trezza et al, 2010). (1) Frequency of pinning: one animal lying with its dorsal surface on the floor with the other animal standing over it. (2) Frequency of pouncing: one animal attempts to nose/rub the nape of the neck of the partner, which is an index of play solicitation
(Supplementary Figure 1). Pinning and pouncing frequencies are considered the most characteristic parameters of social play behavior in rats (Panksepp and Beatty, 1980; Vanderschuren et al, 1997). (3) Time spent on social exploration: one animal sniffing or grooming any part of the partner's body. This is a measure of general social interest.

\section{Statistical Analysis}

Data were analyzed using SPSS software 15.0 for Windows and expressed as mean \pm SEM. To correct for differences in earned social interaction time, the frequency of pinning and pouncing and the duration of social exploration during operant conditioning were calculated per $\min$ or as a percentage of the interaction time, respectively. Pinning, pouncing, social exploration, rewards obtained and inactive lever presses were analyzed using a paired Student's $t$-test with isolation time as within-subjects factor or using a repeated measures ANOVA with drug/dose as withinsubjects factor followed by a paired Student's $t$-test when appropriate. Breakpoints under the PR schedule of reinforcement, ie, the highest number of lever presses made for a single reward in a session, are derived from an escalating curve, which violates the homogeneity of variance. Therefore, breakpoints were analyzed using the non-parametric Friedman test, followed by a post hoc Wilcoxon signed ranks test when appropriate, or using a Wilcoxon signed ranks test when only two groups were compared.

\section{RESULTS}

\section{Validation of the Operant Conditioning Task}

To verify that our operant conditioning task was sensitive to differences in social motivation, we compared rats that were socially isolated for 2 or $24 \mathrm{~h}$, since these isolation periods are known to induce moderate and maximal increases in social play behavior, respectively (Niesink and van Ree, 1989; Vanderschuren et al, 1995, 2008). All rats acquired the task, ie, pressed the active lever for the opportunity for a social interaction under the FR-1 schedule of reinforcement. However, only after $24 \mathrm{~h}$ of isolation did all tested animals $(6 / 6)$ reach performance criterion under the FR-1 schedule of reinforcement within 8 days of training, whereas only onethird (2/6) of the animals isolated for $2 \mathrm{~h}$ reached criterion (data not shown). Next, a group of rats was trained under the PR schedule of reinforcement, and tested after either 2 or $24 \mathrm{~h}$ of social isolation in a within-subjects design. After $24 \mathrm{~h}$ isolation, the rats obtained more rewards $(t=5.15, \mathrm{df}=13$, $p<0.001)$ (Figure 1a), reached a higher breakpoint $(Z=$ $-2.97, p=0.003)$ (Figure $1 \mathrm{~b}$ ), pinned more $(t=3.82, \mathrm{df}=13$, $p=0.002$; Figure 1c) than after $2 \mathrm{~h}$ of social isolation. Social exploration $(t=-0.19, \mathrm{df}=13, p=0.85$; Figure $1 \mathrm{~d})$ and inactive lever presses (Supplementary Table 1) were not different after 2 or $24 \mathrm{~h}$ of social isolation.

\section{Methylphenidate and Cocaine Enhance Operant Responding, but Reduce Social Play Behavior}

Treatment with methylphenidate $(1-3 \mathrm{mg} / \mathrm{kg})$ enhanced the number of rewards obtained $\left(F_{\text {treatment }}(2,10)=19.94\right.$, 


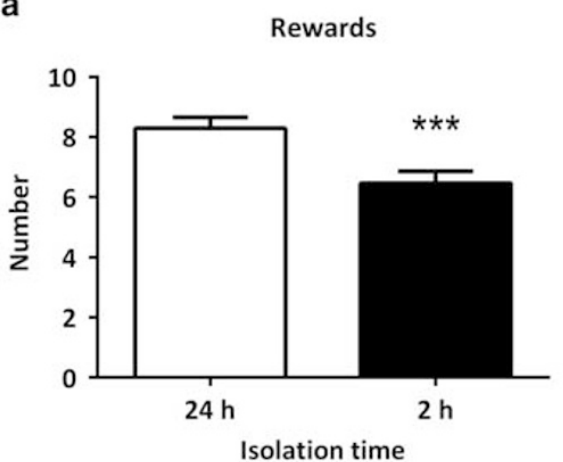

C

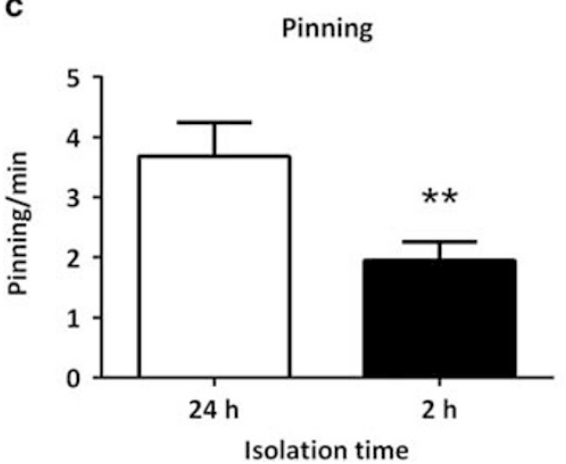

b

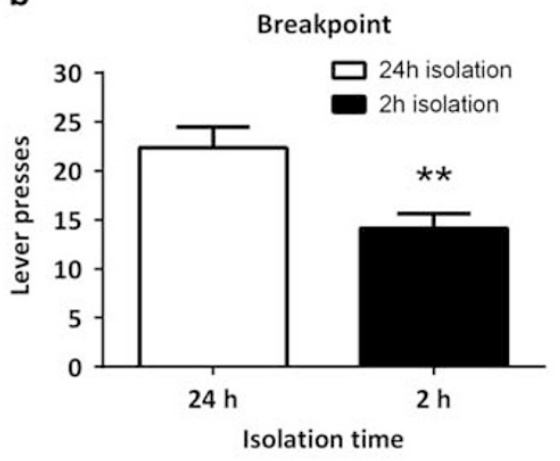

d

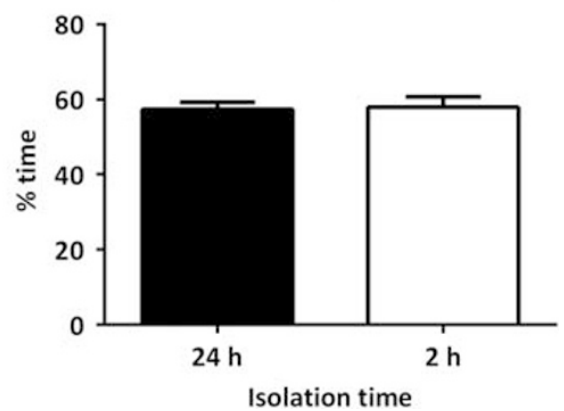

Figure I Effect of social isolation duration on responding for social play behavior. After $24 \mathrm{~h}$ of social isolation, rats obtained more rewards (a) and reached a higher breakpoint (ie, the largest number of lever presses made for a single reward) (b) than after $2 \mathrm{~h}$ of social isolation. Frequency of pinning was higher after $24 \mathrm{~h}$ of isolation (c), whereas social exploration did not differ as a result of isolation (d). $n=14$; all rats were tested after both 2 and $24 \mathrm{~h}$ of social isolation. Data are presented as mean+SEM. *** $p<0.01$, ***** $<<0.001$.

$p<0.001)$, the breakpoint $\left(X^{2}=8.27, \mathrm{df}=2, p=0.02\right)$ (Figure $2 \mathrm{a}$ and $\mathrm{b}$ ), but not inactive lever presses (Supplementary Table 1). However, methylphenidate treatment decreased the frequency of pinning $\left(F_{\text {treatment }}(2,10)=65.97, p<0.001\right)$ (Figure $2 \mathrm{c}$ ) and increased the duration of social exploration $\left(F_{\text {treatment }}(2,10)=8.73, p=0.01\right)$ (Figure $\left.2 \mathrm{~d}\right)$. Treatment with cocaine $(5-10 \mathrm{mg} / \mathrm{kg})$ enhanced the number of rewards obtained $\left(F_{\text {treatment }}(3,12)=3.64, p<0.05\right)$ (Figure $\left.2 \mathrm{e}\right)$, the breakpoint $\left(X^{2}=7.89, \mathrm{df}=3, p<0.05\right)$ (Figure $\left.2 \mathrm{f}\right)$, but not inactive lever presses (Supplementary Table 1). Cocaine treatment decreased the frequency of pinning $\left(F_{\text {treatment }}\right.$ $(3,12)=4.36, p=0.03$ ) (Figure $2 \mathrm{~g}$ ), and did not affect the duration of social exploration $\left(F_{\text {treatment }}(3,12)=1.02\right.$, $p=0.42)$ (Figure $2 \mathrm{~h}$ ).

\section{Selective Inhibition of Dopamine or Noradrenaline Reuptake Differentially Affects Operant Responding and Social Play}

To investigate the role of dopamine and noradrenaline neurotransmission in responding for social play separately, we treated rats with the dopamine reuptake inhibitor GBR-12909 or the noradrenaline reuptake inhibitor atomoxetine. Treatment with GBR-12909 $(3-10 \mathrm{mg} / \mathrm{kg})$ increased the number of rewards obtained $\left(F_{\text {treatment }}(2,20)=5.49\right.$, $p=0.01)$ (Figure 3a) and the breakpoint $\left(X^{2}=8.26, \mathrm{df}=2\right.$, $p=0.02$ ) (Figure $3 b$ ), but not inactive lever presses (Supplementary Table 1). GBR-12909 treatment did not affect pinning $\left(F_{\text {treatment }}(2,20)=2.54, p=0.10\right)$ (Figure $3 c$ ) or social exploration $\quad\left(F_{\text {treatment }}(2,20)=0.95, \quad p=0.41\right)$ (Figure 3d).

Administration of atomoxetine $(1-3 \mathrm{mg} / \mathrm{kg})$ reduced the number of rewards obtained $\left(F_{\text {treatment }}(2,14)=48.31, p<0.001\right)$ (Figure 3e), the breakpoint $\left(X^{2}=15.00, \mathrm{df}=2, p<0.001\right)$ (Figure 3f) and inactive lever presses (Supplementary Table 1). Atomoxetine treatment reduced pinning $\left(F_{\text {treatment }}(2,14)=\right.$ 9.65, $p=0.002$ ) (Figure 3g) but not social exploration $\left(F_{\text {treatment }}(2,14)=2.01, p=0.17\right)$ (Figure $\left.3 \mathrm{~h}\right)$.

\section{Doubly Dissociable Roles for Dopamine and Noradrenaline Receptors in the Effects of Methylphenidate on Operant Responding and Social Play Expression}

The data presented above, combined with our previous work (Vanderschuren et al, 2008; Achterberg et al, 2015) suggest that the effects of methylphenidate on the motivation for and the expression of social play are the result of increases in dopamine and noradrenaline neurotransmission, respectively. To investigate this possibility directly, we assessed the effect of methylphenidate on social play motivation and expression after pretreatment with the dopamine receptor antagonist $\alpha$-flupenthixol and the $\alpha 2$-adrenoceptor antagonist RX821002, respectively. At the doses used, $\alpha$-flupenthixol and RX821002 had no effect on the parameters measured, albeit that treatment with a higher dose of $\alpha$-flupenthixol reduced responding for social play, but not pinning or social exploration (Supplementary Figures 2 and 3). 
a

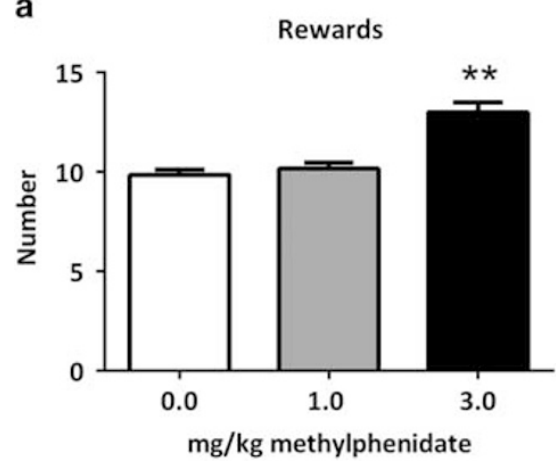

C

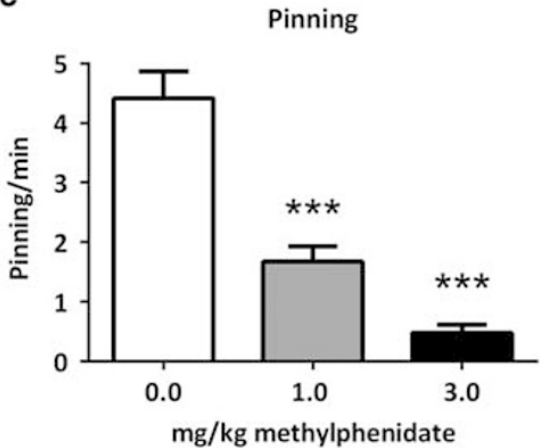

e

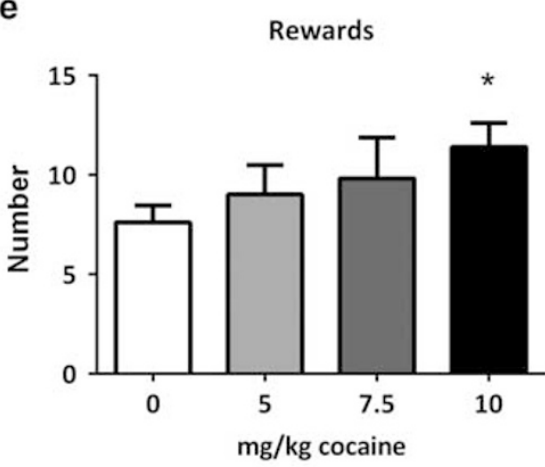

g

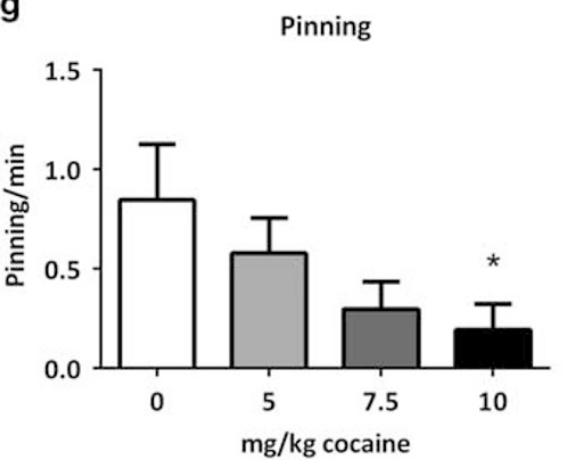

b

Breakpoint

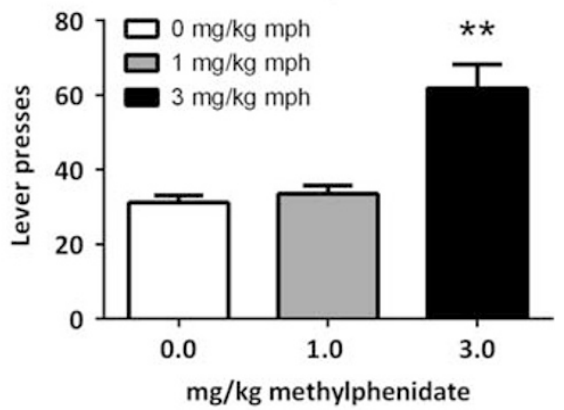

d

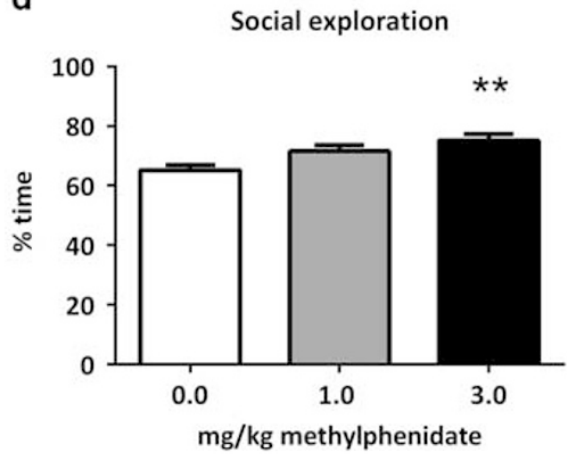

$\mathbf{f}$

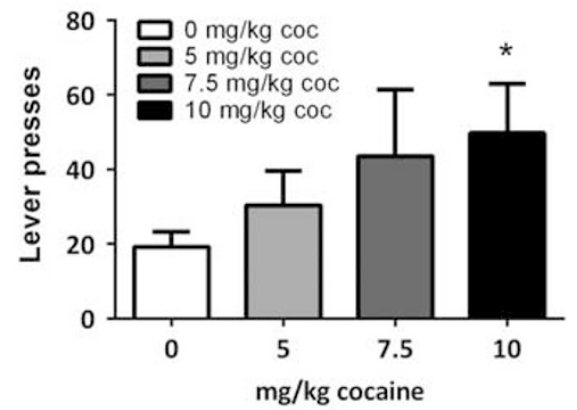

h

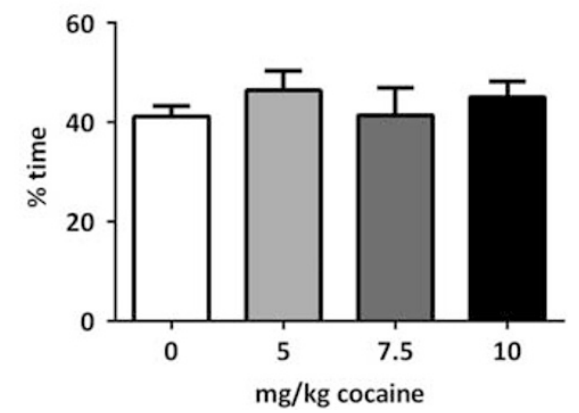

Figure 2 Methylphenidate $(\mathrm{mph} ; n=6)$ and cocaine $(\operatorname{coc} ; n=5)$ enhanced operant responding, but inhibited the expression of social play. Treatment with methylphenidate ( $1-3 \mathrm{mg} / \mathrm{kg}$, s.c.) and cocaine $(5-10 \mathrm{mg} / \mathrm{kg}$, s.c.) enhanced the number of rewards obtained (a, e) and the breakpoint (b, f). Both treatments reduced the frequency of pinning $(c, g)$. Methylphenidate enhanced, while cocaine did not affect, the time spent on social exploratory behavior ( $d$, $h$ ). Data are presented as mean+SEM. ${ }^{*} p<0.05,{ }^{*} * 0.01$, $* * * * 0.001$, relative to saline $(0 \mathrm{mg} / \mathrm{kg} \mathrm{mph} / \mathrm{coc})$ treatment. 


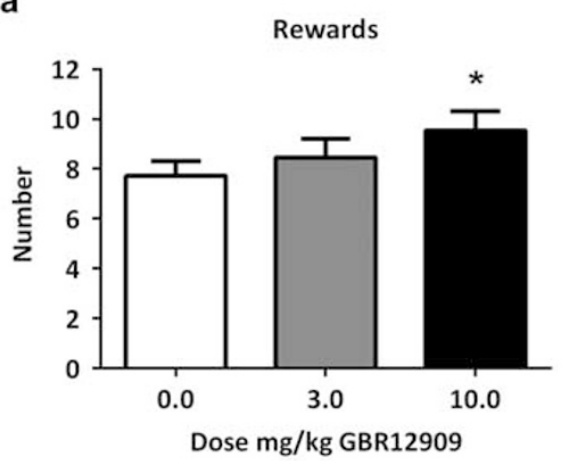

C

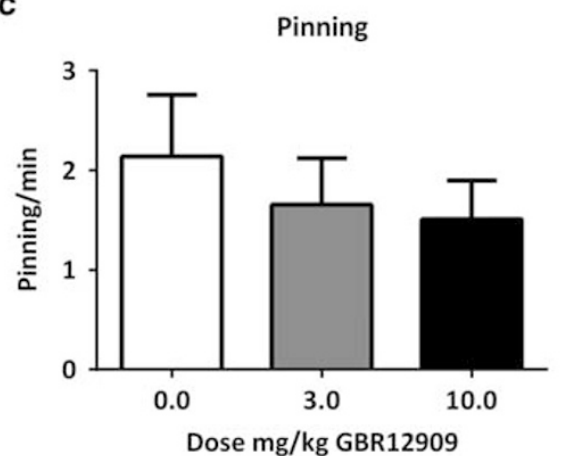

e

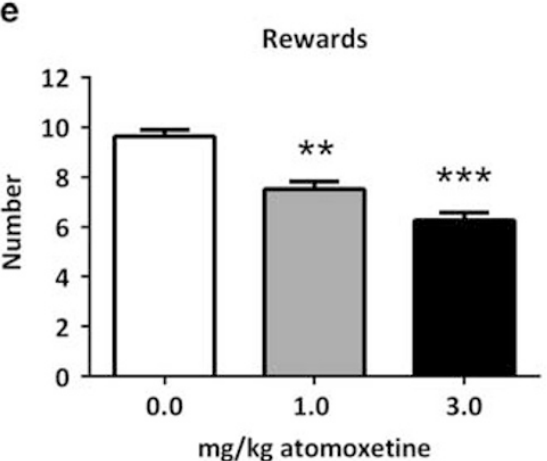

g
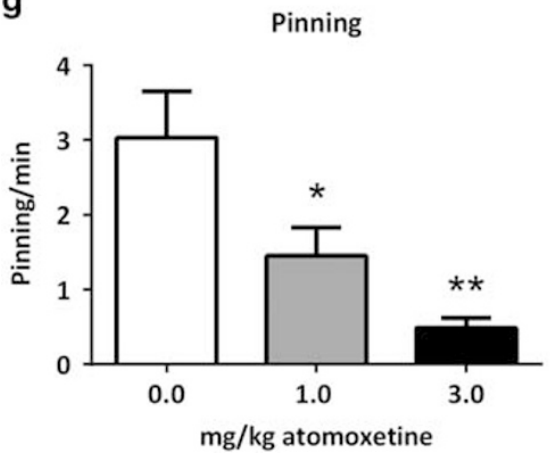

b

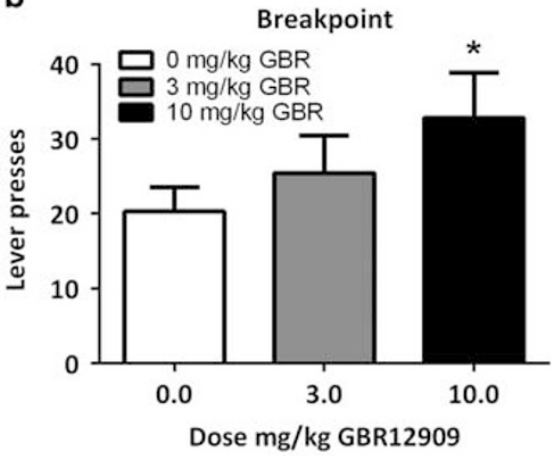

d

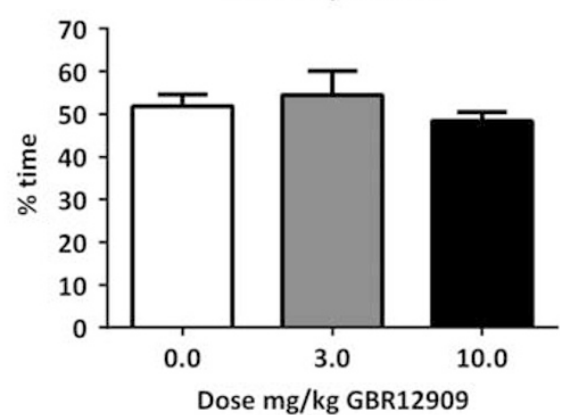

f

Breakpoint

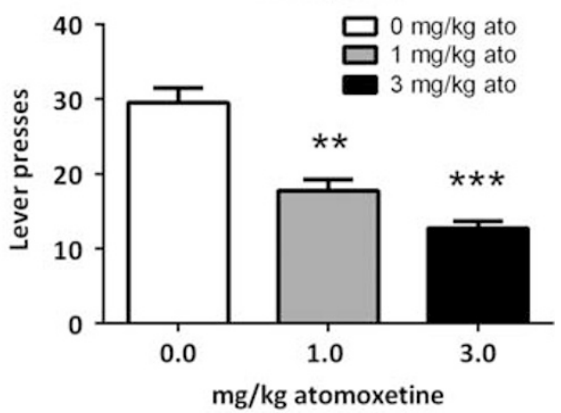

h

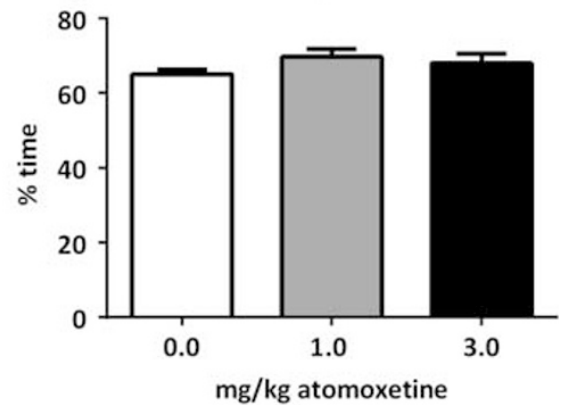

Figure 3 The effect of GBR-I 2909 (GBR; $n=1$ I) and atomoxetine (ato; $n=8$ ) on operant responding for social play behavior. Treatment with GBR- I2909 (3-10 mg/kg, s.c.) enhanced responding for social play. GBR- 2909 increased the number of rewards obtained (a) and the breakpoint (b). Administration of GBR-12909 did not affect the frequency of pinning (c), or the time spent on social exploration (d). Treatment with atomoxetine (I-3 mg/ $/ \mathrm{kg}$, i.p.) reduced operant responding and social play behavior. The number of rewards obtained was reduced (e) and the breakpoint was lower ( $f$ ). In addition, the frequency of

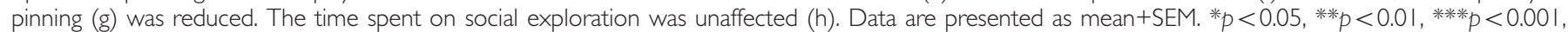
relative to saline $(0 \mathrm{mg} / \mathrm{kg} \mathrm{GBR} / \mathrm{ato})$ treatment. 
a

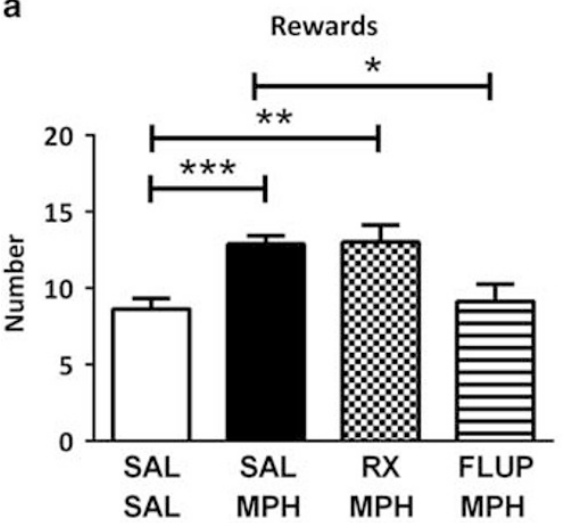

C

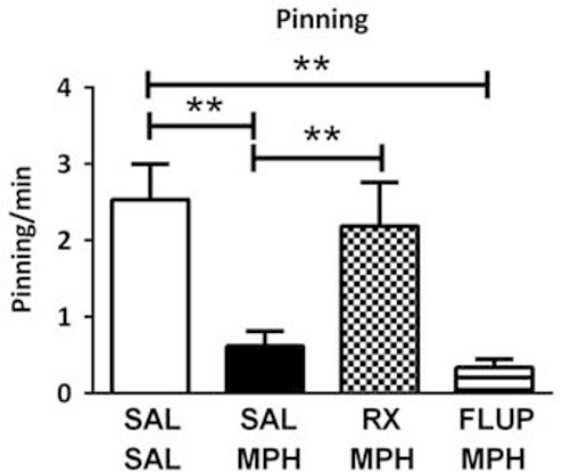

b

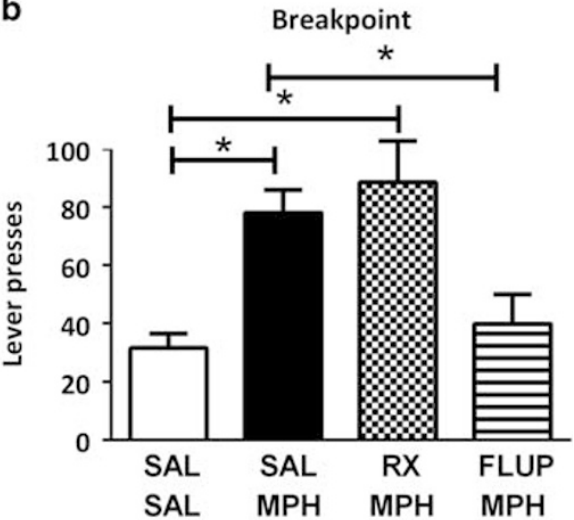

d

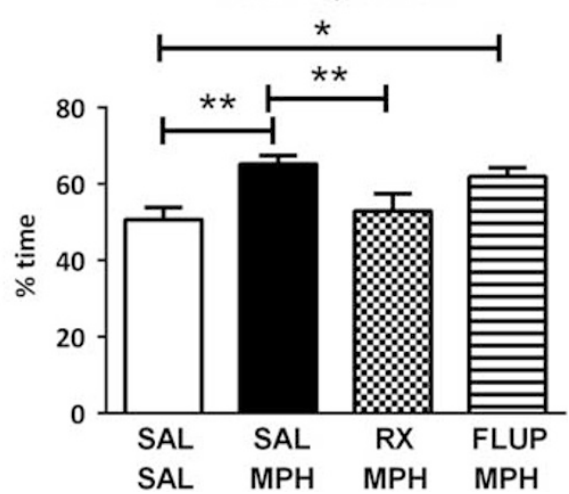

Figure 4 A double dissociation in the effect of methylphenidate on operant responding for social play behavior $(n=8)$. Methylphenidate (MPH; $3 \mathrm{mg} / \mathrm{kg}$, s.c.) increased the number of obtained rewards (a) and the breakpoint (b); this effect was prevented by pretreatment with $\alpha$-flupenthixol (FLUP; 0.125 mg/kg, i.p.) but not $R \times 821002$ ( $R X ; 0.2 \mathrm{mg} / \mathrm{kg}$, i.p.). Methylphenidate reduced the frequency of pinning (c) and increased the time spent on social exploration (d); this effect was prevented by pretreatment with RX821002, but not $\alpha$-flupenthixol. SAL, saline. Data are presented as mean+SEM. * $p<0.05$, *** $p<0.0$ I, **** $p<0.00$ I.

Treatment with methylphenidate, in combination with $\alpha$-flupenthixol, RX821002 or vehicle, affected the number of rewards obtained $\left(F_{\text {treatment }}(3,21)=10.51, \quad p<0.001\right)$, break point $\left(X^{2}=13.50, \quad \mathrm{df}=2, \quad p=0.004\right)$, pinning $\left(F_{\text {treatment }}(3,21)=10.09, \quad p=0.002\right)$, and social exploration ( $\left.F_{\text {treatment }}(3,21)=5.07, \quad p=0.002\right)$, but not inactive lever presses (Supplementary Table 1). Post hoc tests showed that, consistent with the previous experiment, $3 \mathrm{mg} / \mathrm{kg}$ methylphenidate increased the number of rewards obtained and breakpoint, decreased pinning and increased social exploratory behavior. Pretreatment with RX821002 $(0.2 \mathrm{mg} / \mathrm{kg})$ did not antagonize the increase in rewards obtained and breakpoint induced by methylphenidate, but it counteracted the effects of methylphenidate on pinning and social exploration. In contrast, pretreatment with $\alpha$-flupenthixol $(0.125 \mathrm{mg} / \mathrm{kg})$ antagonized the effects of methylphenidate on rewards obtained and breakpoint, but not the effects of methylphenidate on pinning and social exploration (Figure $4 \mathrm{a}-\mathrm{d}$ ).

\section{Cocaine Enhances Operant Responding via Dopaminergic Neurotransmission, but its Effect on Expression of Social Play is Dopamine-Independent}

On the basis of the data presented above, we reasoned that the effect of cocaine on responding for social play are mediated by dopaminergic neurotransmission. In contrast, we have recently shown that the play-suppressant effect of cocaine is not altered by pretreatment with the dopamine receptor antagonist $\alpha$-flupenthixol (Achterberg et al, 2014). We therefore tested whether pretreatment with $\alpha$-flupenthixol influences the effect of cocaine on operant responding, and the expression of social play during reinforced periods.

Treatment with cocaine, in combination with $\alpha$-flupenthixol or vehicle, affected the number of rewards obtained $\left(F_{\text {treatment }}(3,18)=21.53, \quad p<0.001\right)$, breakpoint $\left(X^{2}=13.57\right.$, $\mathrm{df}=3, p=0.004)$, pinning $\left(F_{\text {treatment }}(3,18)=10.74, p=0.008\right)$ but not social exploration $\left(F_{\text {treatment }}(3,18)=0.45, p=0.72\right)$ or inactive lever presses (Supplementary Table 1). Post hoc tests revealed that treatment with $10 \mathrm{mg} / \mathrm{kg}$ cocaine increased rewards obtained and breakpoint, decreased pinning and did not affect social exploratory behavior. Pretreatment with $\alpha$ flupenthixol $(0.125 \mathrm{mg} / \mathrm{kg}$, i.p.) antagonized the effects of cocaine on rewards obtained and breakpoint, but not the effect of cocaine on pinning (Figure 5a-d).

All drug treatments tested altered pinning and pouncing in the same direction (for pouncing data see Supplementary Figure 1).

\section{DISCUSSION}

\section{An Operant Conditioning Task for Social Play}

The purpose of this study was to investigate the role of dopamine and noradrenaline in the incentive motivational 


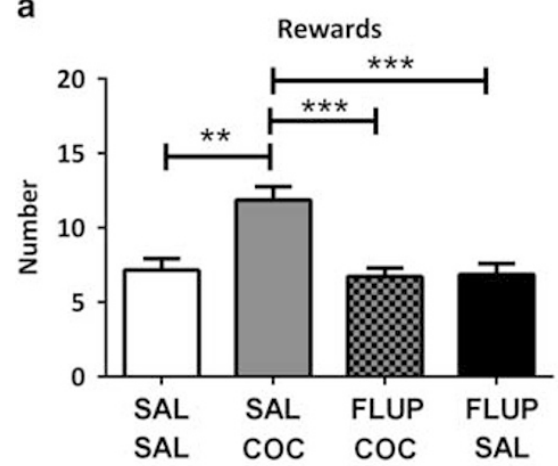

C

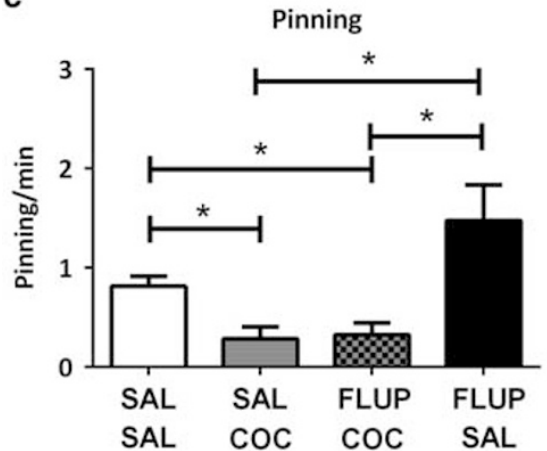

b

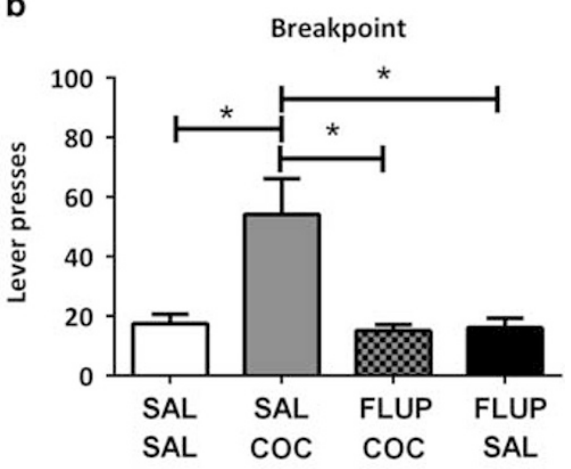

d

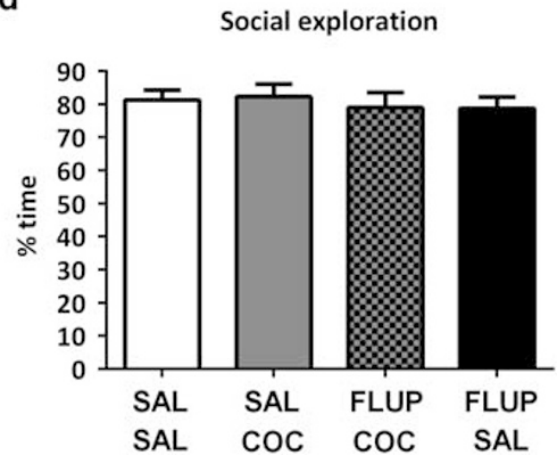

Figure 5 Cocaine enhances responding for social play behavior via dopaminergic neurotransmission $(n=7)$. Cocaine $(C O C ; 10$ mg $/ \mathrm{kg}$, s.c.) increased the number of obtained rewards (a) and the breakpoint (b). This effect was prevented by pretreatment with $\alpha$-flupenthixol (FLUP; 0.125 mg/kg, i.p.). Cocaine reduced the frequency of pinning (c) but did not affect the time spent on social exploration (d). The effect of cocaine on pinning was not altered by pre/ treatment with $\alpha$-flupenthixol. SAL, saline. Data are presented as mean+SEM. $* p<0.05$, $* * * 0.01, * * * p<0.001$.

properties of social play behavior in rats. To that aim, we developed an operant conditioning task, in which rats were trained to lever press under a PR schedule of reinforcement for brief periods of social play. Responding under a PR schedule of reinforcement is a widely used method to measure the motivational properties of rewards (Hodos, 1961; Richardson and Roberts, 1996). In the past, lever pressing for play (with a human experimenter) was demonstrated in chimpanzees (Mason et al, 1962), and T-maze tasks have been used to assess motivational aspects of social play behavior in rats (Humphreys and Einon, 1981; Normansell and Panksepp, 1990). To the best of our knowledge, however, the present study is the first to show that rats are willing to lever press for social play reinforcement. This demonstration fits into a larger literature that has described reinforcing properties of a wide variety of social behaviors, including maternal, sexual, and aggressive behavior (Everitt, 1990; Fish et al, 2002; Trezza et al, 2011).

As a first step, to validate our approach, we investigated whether changing the duration of social isolation before training and testing would alter responding. There is a close relationship between the length of social isolation and the amount of social play behavior expressed during testing (Niesink and Van Ree, 1989; Vanderschuren et al, 1995, 2008). Therefore, we assumed that longer social isolation would enhance responding for social play as well as its expression. Indeed, animals isolated for $24 \mathrm{~h}$ acquired the operant task faster than animals isolated for $2 \mathrm{~h}$. When the animals were subsequently tested after both isolation periods (ie, all animals were tested after 2 and $24 \mathrm{~h}$ of isolation), we found that $24 \mathrm{~h}$ of social isolation led to higher breakpoints, and that after $24 \mathrm{~h}$ of isolation, the rats earned more social play rewards. Moreover, levels of pinning and pouncing were higher after $24 \mathrm{~h}$ of social isolation, consistent with previous work (Niesink and Van Ree, 1989; Vanderschuren et al, 1995, 2008). These results show that it is possible to measure differences in social play motivation using an operant conditioning task.

These data support the assumption that social play behavior is the most important factor that drives responding in our operant conditioning task. First, there is a substantial literature to show that playful social interaction in rats is more rewarding in place conditioning and T-maze setups than interaction with a drug-treated partner that does show social investigation, but not social play, or with a physically confined partner (Humphreys and Einon, 1981; Calcagnetti and Schechter, 1992; Trezza et al, 2009a, b; Peartree et al, 2012). Second, as discussed above, our data show that isolation for $24 \mathrm{~h}$ enhances acquisition of the task as well as operant responding and social play behavior (but not social exploratory behavior) during testing, compared with a $2 \mathrm{~h}$ isolation period. Third, in an initial pilot experiment we found that rats trained in the task without a social partner (ie, responding on the active lever resulted in opening of the door and presentation of the cue light only) did not acquire responding under on a schedule that was more demanding than an FR1 schedule (ie, under FR2, FR5 or FR10 schedules of reinforcement), excluding the possibility that the animals were merely responding for door opening, cue light presentation, or access to another compartment of the 
apparatus (data not shown). This latter observation is consistent with data showing that rats will initially press a lever for cue light presentation, but that this responding quickly extinguishes over days of testing (Deroche-Gamonet et al, 2002).

\section{Dissociable Roles of Dopamine and Noradrenaline in Social Play Motivation and Expression}

Consistent with the well-known role of dopamine, in particular in the nucleus accumbens, in incentive motivation (Kelley, 2004; Barbano and Cador, 2007; Robbins and Everitt, 2007; Berridge, 2007; Salamone and Correa, 2012), treatment with drugs that increase extracellular dopamine concentrations, ie, methylphenidate, cocaine, and GBR12909, increased responding. Moreover, the effects of methylphenidate and cocaine on lever pressing were prevented by pretreatment with the dopamine receptor antagonist $\alpha$-flupenthixol, whereas a higher dose of $\alpha$-flupenthixol reduced responding for social play by itself. These effects were behaviorally specific, since responding on the inactive lever was not affected by these drug treatments, and the expression of social play during reinforced periods was not affected by GBR-12909 and $\alpha$-flupenthixol, and reduced by methylphenidate and cocaine, consistent with our previous observations (Vanderschuren et al, 2008; Trezza and Vanderschuren, 2009; Achterberg et al, 2014). Changes in accumbens dopamine levels are known to affect the motivation for a reward, without markedly changing reward consumption (for reviews see: Kelley, 2004; Barbano and Cador, 2007; Robbins and Everitt, 2007; Berridge, 2007; Salamone and Correa, 2012). For example, administration of amphetamine into the nucleus accumbens enhances operant responding for food (Zhang et al, 2003), but not food consumption (Hanlon et al, 2004). Our observations are therefore consistent with the view that dopaminergic neurotransmission has a critical role in incentive motivation, that is, in the invigoration of appetitive approach towards a goal (Robbins and Everitt, 2007; Salamone and Correa, 2012), but not in reward consumption.

In keeping with previous work (Beatty et al, 1982; Ferguson et al, 2000; Vanderschuren et al, 2008; Achterberg et al, 2014), treatment with the psychostimulant drugs methylphenidate and cocaine reduced the expression of social play behavior during reinforced play periods, despite the fact that they enhanced lever pressing. At first glance, these findings suggest that behaviors other than social play serve as a reinforcer after psychostimulant treatment (Thiel et al, 2008). For example, rats treated with MDMA show increases in passive social behavior (Thompson et al, 2007), and rewarding properties of the tactile aspects of social interaction have indeed been demonstrated (Kummer et al, 2011). Although in our experiments, passive social interaction was hardly ever observed, the possibility that social exploratory behavior contributed to responding after treatment with cocaine or methylphenidate can as yet not be excluded.

Our observations resonate well with the notion that different components of reward behavior, such as pleasure, motivation, consumption, and learning are mediated by dissociable neural mechanisms (Kelley, 2004; Barbano and Cador, 2007; Robbins and Everitt, 2007; Berridge et al, 2009;
Salamone and Correa, 2012; Berridge and Kringelbach, 2015). Indeed, although the effects of methylphenidate and cocaine on operant responding were mediated by dopaminergic neurotransmission, their effects on the expression of social play were not. In fact, the play-suppressant effect of methylphenidate was prevented by pretreatment with the $\alpha 2$-adrenoceptor antagonist RX821002 (see also Vanderschuren et al, 2008), which left its effect on operant responding unaltered. Together, these results demonstrate a double dissociation in the effects of methylphenidate on social play behavior. The increasing effects of methylphenidate on social play motivation are mediated through stimulation of dopamine receptors, whereas its suppressant effects on the expression of social play behavior rely on $\alpha 2$ adrenoceptor stimulation. It is therefore likely that treatment with methylphenidate, by virtue of its effects on nucleus accumbens dopaminergic neurotransmission (Gerasimov et al, 2000; Kuczenski and Segal, 2001; Bymaster et al, 2002), makes animals more motivated for social play, yet through its effects on prefrontal and subcortical limbic noradrenaline (Achterberg et al, 2015) makes animals less capable of actually performing the playful actions.

Treatment with the noradrenaline reuptake inhibitor atomoxetine reduced the expression of social play behavior as well as operant responding for social play. We have previously shown that the reduction in the expression of social play behavior induced by atomoxetine depends upon stimulation of $\alpha 2$-adrenoceptors (Vanderschuren et al, 2008). These results indicate that enhanced noradrenaline signaling reduces the motivation for, as well as the expression of social play behavior. Importantly, atomoxetine has been shown to increase extracellular prefrontal noradrenaline, prefrontal dopamine, and subcortical noradrenaline concentrations, but not to alter nucleus accumbens dopamine activity (Bymaster et al, 2002; Swanson et al, 2006). This likely explains why methylphenidate increases responding for social play, but atomoxetine does not. We have recently shown that atomoxetine, like methylphenidate, reduces social play behavior after infusion into the medial prefrontal cortex, basolateral amygdala, and habenula (Achterberg et al, 2015). On the basis of those data, we argued that increased noradrenaline activity in these regions interferes with certain cognitive and emotional aspects of social play. In the present context, this may mean that atomoxetine treatment renders animals less capable of performing social play activities, which may then, in the absence of changes in mesoaccumbens dopamine neurotransmission, lead to a reduction in the motivation to respond for social play. However, a direct effect of atomoxetine on the motivation for social play cannot be ruled out.

\section{Concluding Remarks}

The present study adds a new dimension to the analysis of social play behavior in rats, by introducing a method by which the incentive motivational properties of social play can be explicitly assessed. Furthermore, our data show that dopaminergic and noradrenergic signaling affect different aspects of social play behavior. Enhancement of endogenous dopamine levels increases the motivation for social play, but does not alter its expression. Increases in noradrenergic neurotransmission reduce the expression as well as the 
motivation for social play. These data provide new insights into the intricate mechanisms by which catecholamines modulate social play behavior in rats. Elucidating the neural underpinnings of social behavior in the young may increase our understanding of normal, adaptive social development, and shed light on the pathophysiology of childhood and adolescent psychiatric disorders characterized by aberrant social behavior.

\section{FUNDING AND DISCLOSURE}

The authors declare that, except for income received from their primary employers, no financial support or compensation has been received from any individual or corporate entity over the past 3 years for research or professional service and there are no personal financial holdings that could be perceived as constituting a potential conflict of interest.

\section{ACKNOWLEDGMENTS}

Supported by National Institute on Drug Abuse Grant R01 DA022628 (LJMJV), Netherlands Organization for Scientific Research (NWO) Veni grant 91611052 (VT) and Marie Curie Career Reintegration Grant PCIG09-GA-2011293589 (VT).

\section{REFERENCES}

Achterberg EJM, Trezza V, Siviy SM, Schrama L, Schoffelmeer ANM, Vanderschuren LJMJ (2014). Amphetamine and cocaine suppress social play behavior in rats through distinct mechanisms. Psychopharmacology 231: 1503-1515.

Achterberg EJM, van Kerkhof LWM, Damsteegt R, Trezza V, Vanderschuren LJMJ (2015). Methylphenidate and atomoxetine inhibit social play behavior through prefrontal and subcortical limbic mechanisms in rats. J Neurosci 35: 161-169.

Aston-Jones G, Cohen JD (2005). An integrative theory of locus coeruleus-norepinephrine function: adaptive gain and optimal performance. Annu Rev Neurosci 28: 403-450.

Baarendse PJJ, Counotte DS, O'Donnell P, Vanderschuren LJMJ (2013a). Social experience during adolescence is critical for the development of cognitive control and dopamine modulation of prefrontal cortex function. Neuropsychopharmacology 38: 1485-1494.

Baarendse PJJ, Vanderschuren LJMJ (2012). Dissociable effects of monoamine reuptake inhibitors on distinct forms of impulsive behavior in rats. Psychopharmacology 219: 313-326.

Baarendse PJJ, Winstanley CA, Vanderschuren LJMJ (2013b). Simultaneous blockade of dopamine and noradrenaline reuptake promotes disadvantageous decision making in a rat gambling task. Psychopharmacology 225: 719-731.

Barbano MF, Cador M (2007). Opioids for hedonic experience and dopamine to get ready for it. Psychopharmacology 191: 497-506.

Beatty WW, Dodge AM, Dodge LJ, White K, Panksepp J (1982). Psychomotor stimulants, social deprivation and play in juvenile rats. Pharmacol Biochem Behav 16: 417-422.

Berridge CW, Waterhouse BD (2003). The locus coeruleusnoradrenergic system: modulation of behavioral state and statedependent cognitive processes. Brain Res Rev 42: 33-84.

Berridge KC (2007). The debate over dopamine's role in reward: the case for incentive salience. Psychopharmacology 191: 391-431.
Berridge KC, Robinson TE, Aldridge JW (2009). Dissecting components of reward: 'liking', 'wanting', and learning. Curr Opin Pharmacol 9: 65-73.

Berridge KC, Kringelbach ML (2015). Pleasure systems in the brain. Neuron 86: 646-664.

Bouret S, Richmond BJ (2015). Sensitivity of locus ceruleus neurons to reward value for goal-directed actions. I Neurosci 35: 4005-4014.

Bymaster FP, Katner JS, Nelson DL, Hemrick-Luecke SK, Threlkeld PG, Heiligenstein JH et al (2002). Atomoxetine increases extracellular levels of norepinephrine and dopamine in prefrontal cortex of rat: a potential mechanism for efficacy in attention deficit/hyperactivity disorder. Neuropsychopharmacology 27: 699-711.

Calcagnetti DJ, Schechter MD (1992). Place conditioning reveals the rewarding aspect of social interaction in juvenile rats. Physiol Behav 51: 667-672.

Crowder WF, Hutto CW Jr. (1992). Operant place conditioning measures examined using two nondrug reinforcers. Pharmacol Biochem Behav 41: 817-824.

Deroche-Gamonet V, Piat F, Le Moal M, Piazza PV (2002). Influence of cue-conditioning on acquisition, maintenance and relapse of cocaine intravenous self-administration. Eur J Neurosci 15: $1363-1370$.

Douglas LA, Varlinskaya EI, Spear LP (2004). Rewarding properties of social interactions in adolescent and adult male and female rats: impact of social versus isolate housing of subjects and partners. Dev Psychobiol 45: 153-162.

Everitt BJ (1990). Sexual motivation: a neural and behavioural analysis of the mechanisms underlying appetitive and copulatory responses of male rats. Neurosci Biobehav Rev 14: 217-232.

Ferguson SA, Frisby NB, Ali SF (2000). Acute effects of cocaine on play behaviour of rats. Behav Pharmacol 11: 175-179.

Fish EW, De Bold JF, Miczek KA (2002). Aggressive behavior as a reinforcer in mice: activation by allopregnanolone. Psychopharmacology 163: 459-466.

Gerasimov MR, Franceschi M, Volkow ND, Gifford A, Gatley SJ, Marsteller D et al (2000). Comparison between intraperitoneal and oral methylphenidate administration: a microdialysis and locomotor activity study. J Pharmacol Exp Ther 295: 51-57.

Graham KL, Burghardt GM (2010). Current perspectives on the biological study of play: signs of progress. Q Rev Biol 85: 393-418.

Hanlon EC, Baldo BA, Sadeghian K, Kelley AE (2004). Increases in food intake or food-seeking behavior induced by GABAergic, opioid, or dopaminergic stimulation of the nucleus accumbens: is it hunger? Psychopharmacology 172: 241-247.

Hodos W (1961). Progressive ratio as a measure of reward strength. Science 134: 934-944.

Humphreys AP, Einon DF (1981). Play as a reinforcer for mazelearning in juvenile rats. Anim Behav 29: 259-270.

Kelley AE (2004). Ventral striatal control of appetitive motivation: role in ingestive behavior and reward-related learning. Neurosci Biobehav Rev 27: 765-776.

Kuczenski R, Segal DS (2001). Locomotor effects of acute and repeated threshold doses of amphetamine and methylphenidate: relative roles of dopamine and norepinephrine. J Pharmacol Exp Ther 296: 876-883.

Kummer K, Klement S, Eggart V, Mayr MJ, Saria A, Zernig G (2011). Conditioned place preference for social interaction in rats: contribution of sensory components. Front Behav Neurosci 5: 80.

Mason WA, Hollis JH, Sharpe LG (1962). Differential responses of chimpanzees to social stimulation. J Comp Physiol Psychol 55: 1105-1110.

Niesink RJM, Van Ree JM (1989). Involvement of opioid and dopaminergic systems in isolation-induced pinning and social grooming of young rats. Neuropharmacology 28: 411-418. 
Normansell L, Panksepp J (1985). Effects of clonidine and yohimbine on the social play of juvenile rats. Pharmacol Biochem Behav 22: 881-883.

Normansell L, Panksepp J (1990). Effects of morphine and naloxone on play-rewarded spatial discrimination in juvenile rats. Dev Psychobiol 23: 75-83.

Panksepp J, Beatty WW (1980). Social deprivation and play in rats. Behav Neural Biol 30: 197-206.

Panksepp J, Siviy SM, Normansell L (1984). The psychobiology of play: theoretical and methodological perspectives. Neurosci Biobehav Rev 8: 465-492.

Peartree NA, Hood LE, Thiel KJ, Sanabria F, Pentkowski NS, Chandler KN et al (2012). Limited physical contact through a mesh barrier is sufficient for social reward-conditioned place preference in adolescent male rats. Physiol Behav 105: 749-756.

Pellis SM, Pellis VC (1987). Play-fighting differs from serious fighting in both target of attack and tactics of fighting in the laboratory rat Rattus norvegicus. Aggress Behav 13: 227-242.

Pellis SM, Pellis VC (2009). The Playful Brain. OneWorld Publications: Oxford, UK.

Richardson NR, Roberts DC (1996). Progressive ratio schedules in drug self-administration studies in rats: a method to evaluate reinforcing efficacy. J Neurosci Methods 66: 1-11.

Robbins TW, Everitt BJ (2007). A role for mesencephalic dopamine in activation: commentary on Berridge (2006). Psychopharmacology (Berl) 191: 433-437.

Salamone JD, Correa M (2012). The mysterious motivational functions of mesolimbic dopamine. Neuron 76: 470-485.

Siviy SM, Baliko CN (2000). A further characterization of alpha-2 adrenoceptor involvement in the rough-and-tumble play of juvenile rats. Dev Psychobiol 37: 25-34.

Siviy SM, Fleischhauer AE, Kerrigan LA, Kuhlman SJ (1996). D2 dopamine receptor involvement in the rough-and-tumble play behavior of juvenile rats. Behav Neurosci 110: 1168-1176.

Siviy SM, Fleischhauer AE, Kuhlman SJ, Atrens DM (1994). Effects of alpha-2 adrenoceptor antagonists on rough-and-tumble play in juvenile rats: evidence for a site of action independent of nonadrenoceptor imidazoline binding sites. Psychopharmacology 113: 493-499.

Siviy SM, Panksepp J (1987). Sensory modulation of juvenile play in rats. Dev Psychobiol 20: 39-55.

Siviy SM, Panksepp J (2011). In search of the neurobiological substrates for social playfulness in mammalian brains. Neurosci Biobehav Rev 35: 1821-1830.

Špinka M, Newberry RC, Bekoff M (2001). Mammalian play: training for the unexpected. Q Rev Biol 76: 141-168.

Swanson CJ, Perry KW, Koch-Krueger S, Katner J, Svensson KA, Bymaster FP (2006). Effect of the attention deficit/hyperactivity disorder drug atomoxetine on extracellular concentrations of norepinephrine and dopamine in several brain regions of the rat. Neuropharmacology 50: 755-760.
Thiel KJ, Okun AC, Neisewander JL (2008). Social rewardconditioned place preference: a model revealing an interaction between cocaine and social context rewards in rats. Drug Alcohol Depend 96: 202-212.

Thompson MR, Callaghan PD, Hunt GE, Cornish JL, McGregor IS (2007). A role for oxytocin and 5- $\mathrm{HT}_{1 \mathrm{~A}}$ receptors in the prosocial effects of 3,4 methylenedioxymethamphetamine ("ecstasy"). Neuroscience 146: 509-514.

Trezza V, Baarendse PJJ, Vanderschuren LJMJ (2009b). Prosocial effects of nicotine and ethanol in adolescent rats through partially dissociable neurobehavioral mechanisms. Neuropsychopharmacology 34: 2560-2573.

Trezza V, Baarendse PJJ, Vanderschuren LJMJ (2010). The pleasures of play: pharmacological insights into social reward mechanisms. Trends Pharmacol Sci 31: 463-469.

Trezza V, Campolongo P, Vanderschuren LJMJ (2011). Evaluating the rewarding nature of social interactions in laboratory animals. Dev Cogn Neurosci 1: 444-458.

Trezza V, Damsteegt R, Vanderschuren LJMJ (2009a). Conditioned place preference induced by social play behavior: parametrics, extinction, reinstatement and disruption by methylphenidate. Eur Neuropsychopharmacol 19: 659-669.

Trezza V, Vanderschuren LJMJ (2008). Bidirectional cannabinoid modulation of social behavior in adolescent rats. Psychopharmacology 197: 217-227.

Trezza V, Vanderschuren LJMJ (2009). Divergent effects of anandamide transporter inhibitors with different target selectivity on social play behavior in adolescent rats. J Pharmacol Exp Ther 328: 343-350.

Vanderschuren LJMJ (2010). How the brain makes play fun. Am J of Play 2: 315-337.

Vanderschuren LJMJ, Niesink RJM, Spruijt BM, Van Ree JM (1995). Effects of morphine on different aspects of social play in juvenile rats. Psychopharmacology 117: 225-231.

Vanderschuren LJMJ, Niesink RJM, Van Ree JM (1997). The neurobiology of social play behavior in rats. Neurosci Biobehav Rev 21: 309-326.

Vanderschuren LJMJ, Trezza V (2014). What the laboratory rat has taught us about social play behavior: role in behavioral development and neural mechanisms. Curr Top Behav Neurosci 16: $189-212$.

Vanderschuren LJMJ, Trezza V, Griffioen-Roose S, Schiepers OJG, Van Leeuwen N, De Vries TJ et al (2008). Methylphenidate disrupts social play behavior in adolescent rats. Neuropsychopharmacology 33: 2946-2956.

Ventura R, Latagliata EC, Morrone C, La Mela I, Puglisi-Allegra S (2008). Prefrontal norepinephrine determines attribution of "high" motivational salience. PLoS One 3: e3044.

Zhang M, Balmadrid C, Kelley AE (2003). Nucleus accumbens opioid, GABaergic, and dopaminergic modulation of pala table food motivation: contrasting effects revealed by a progressive ratio study in the rat. Behav Neurosci 117: 202-211.

Supplementary Information accompanies the paper on the Neuropsychopharmacology website (http://www.nature.com/npp) 